\title{
Definition of the Local Geoid Undulation Using Non-contemporary GNSS-Levelling Data on Subsidence Area: Application on the Adriatic Coastline
}

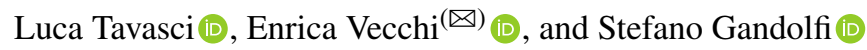 \\ University of Bologna, DICAM, Bologna, Italy \\ \{luca.tavasci, enrica.vecchi\} @unibo.it
}

\begin{abstract}
The knowledge of the so-called geoid undulation, which represents the height of the geoid above a reference ellipsoid, is a fundamental step to link ellipsoidal heights measured using satellite systems and orthometric heights. Several geoid models are available at the time both at the national or global scale, which can be used for the purpose. Another way to define the geoid undulation is to perform joint measures with GNSS and spirit levelling over common benchmarks. This requires onerous measurements that is seldom possible to perform due to their cost. In this work, we evaluated the possibility to define a local model of the geoid undulation using already available spirit levelling orthometric heights and GNSS ellipsoidal heights measured about 13 years later. The test area is the Emilia-Romagna Adriatic coastline, an area of great interest both from the environmental and economic point of view, which is also undergoing consistent subsidence phenomena.

Test results show that the available measurements allow defining a geoid undulation that is coherent with the shape defined by the gravimetric models and also allows to transform ellipsoidal heights into orthometric ones more consistent with the height reference available on the surveyed area. A $7 \mathrm{~cm}$ overall bias with respect to the ITALGEO05 was found, whereas ITG2009 and EGM2008 have higher differences. The use of subsidence models to align over time the coordinates used to define the geoid undulation has proven to be a fundamental step. The analysis on the a-priori uncertainty in the geoid height definition shown that the combined use of much more precise GNSS coordinates and contemporary spirit levelling campaign is necessary to significantly improve the resulting geoid height.
\end{abstract}

Keywords: Geoid · Subsidence · Geoid height · Geoid undulation · GNSS · Spirit levelling $\cdot$ Emilia-Romagna

\section{Introduction}

The accurate estimation of the geoid undulation has become fundamental especially in the last decades with the increasing use of GNSS and other spatial techniques for surveying and monitoring. All the techniques that use satellites orbits as constraints for the

(C) The Author(s) 2022

E. Borgogno-Mondino and P. Zamperlin (Eds.): ASITA 2021, CCIS 1507, pp. 259-270, 2022.

https://doi.org/10.1007/978-3-030-94426-1_19 
final coordinates are bound to relate the height component to the geometric surface of the reference ellipsoid. Such a reference does not consider the local gravitational potential, therefore the so-called ellipsoidal height $(\mathrm{h})$ cannot be used in many technical applications, especially the ones involving water management. The geoid, which represents the equipotential surface of the Earth gravity field passing below the topographic masses and approximating the mean sea level, is the more appropriate reference surface to deal with the common concept of "height" and allows to define the orthometric height $(\mathrm{H})$. The geoid undulation $(\mathrm{N})$ represents the separation between the reference ellipsoid and the geoid itself [1]. It allows calculating the orthometric height also for those points surveyed using a space technique directly providing the ellipsoid height only.

Several models of geoid undulation are available both at the global and regional scale. These models have been developed over time starting from satellite gravimetric measurements and modelling the shape of the geoid using of a certain number (up to 2190) of spherical harmonics. Another way to compute the geoid undulation is to compare over a common point the difference between its ellipsoidal height defined using a GNSS receiver and its pseudo-orthometric height measured through spirit levelling [24]. This cannot be done at the global scale because of limitations in the application of spirit levelling, but it can be useful at the regional scale.

Coastal areas are environments where the correct use of orthometric heights is fundamental, in particular for those regions characterized by flat terrain such as the EmiliaRomagna Adriatic coastline. On this territory, the regional agency for the environmental protection of Emilia-Romagna (Arpae), together with the Department of Civil, Chemical and Environmental Engineering (DICAM) of the University of Bologna, created in 2016 a geodetic infrastructure called Coastal Geodetic Network (RGC) [5], which is composed of 51 benchmarks both suitable for spirit levelling and GNSS surveying. Its main use is the monitoring of the sand erosion along the coastline, but it can be used as support for any survey about the area since the benchmarks coordinates are defined in the national official reference frame (ETRF2000, epoch 2008.0).

In this paper, we investigated the possibility to calculate a GNSS-levelling derived model for the local geoid undulation on the Emilia-Romagna coastal area. This model could provide a way to correct the ellipsoidal heights more consistently with the orthometric data already available.

One of the key points in this work is the unavailability of contemporary measurements with both GNSS and spirit levelling, combined with the fact that the whole area is affected by significant subsidence phenomena [6-8]. Therefore, an appropriate strategy to overcome this problem is proposed, together with a discussion on the expected accuracy of the geoid undulations estimated on site. To do so, 51 benchmarks belonging to the RGC were used.

The experimental data results have been finally compared with the available data from three gravimetric models, namely the Italian official ITALGEO05 [9] the more recent ITG2009 [10] and the EGM2008 [11] global model. A discussion will be provided whether the opportunity of using already existent geomatic data to estimate local models for the geoid height and the requirements necessary to reach an accuracy sufficient to consider such models a trustable reference and a real improvement with respect to global/national ones. 


\section{Dataset}

The Italian Adriatic coast represents a significant area for the national environmental and economic wealth. For this reason, in the last decades, many different authorities have arranged their own monitoring networks, with points distributed along the coastline. These networks have been managed by IGM, RER, Idroser, Agip and, finally, by Arpa which handled the subsidence monitoring network. In 2016, some of the benchmarks belonging to these monitoring networks have been included in the RGC created from the collaboration between Arpae and the DICAM of the University of Bologna [5]. A requirement for the chosen points was the suitability both for spirit levelling surveys and for GNSS measurements. Moreover, to have a proper distribution of the benchmarks along the coast, the spatial density of about one point every $4 \mathrm{~km}$ (Fig. 1) was defined. These benchmarks have been last measured through precise spirit levelling in 1999 and 2005 during campaigns for subsidence monitoring. In the following years Arpa, today Arpae, moved from spirit levelling to the InSAR technique for the monitoring of subsidence phenomena [12], therefore those gathered in 2005 are the most recent data about the orthometric height available for the coastal levelling networks.

In order to reach a more homogeneous spatial distribution of the RGC, during 2019 some new benchmarks were installed and measured. Their orthometric heights have been defined through short levelling stretches linking to the closest existing points belonging to the above-mentioned networks but not suitable for GNSS positioning. Concerning the ellipsoidal heights, GNSS measuring campaigns have been carried out mainly in 20162017 for the first set of points and then integrated in 2019. The measuring campaigns involved static observing sessions ranging between 1 and $2 \mathrm{~h}$ to compute the short baselines linking contiguous points. Despite the poor redundancy due to the network geometry it was possible to adjust the baselines, thus providing the a-posteriori error matrix for each benchmark.

\section{Methods}

As already mentioned, both the orthometric and the ellipsoidal heights of the chosen benchmarks were not referred to the same epoch. Although the undulation value is invariant to the subsidence phenomenon, this can impact the calculation in the case of non-contemporary measurements. For this reason, the computation of the local geoid undulation $\mathrm{N}$ needed for the updating of both the height values to a common epoch. To take into account the subsidence phenomena we used piecewise linear models of height variations. The chosen epoch to which update the height coordinates has been the 2018.0, being it about the middle of GNSS surveying campaigns and a quite recent time.

Starting from the year 2006, the Emilia-Romagna region provides Subsidence Models for the area based on InSAR data every five years [12-14]: currently there is the availability of models for the periods 2006-2011 and 2011-2016. We extrapolated data of the later periods at epoch 2018.0 since the up-to-date model is still not available.

As for ellipsoidal heights, values for each benchmark were updated at epoch 2018.0 following the formula:

$$
\mathrm{h}_{2018.0}=\mathrm{h}_{\mathrm{t}}+\Delta \mathrm{t} * \mathrm{v}_{\mathrm{s}}
$$




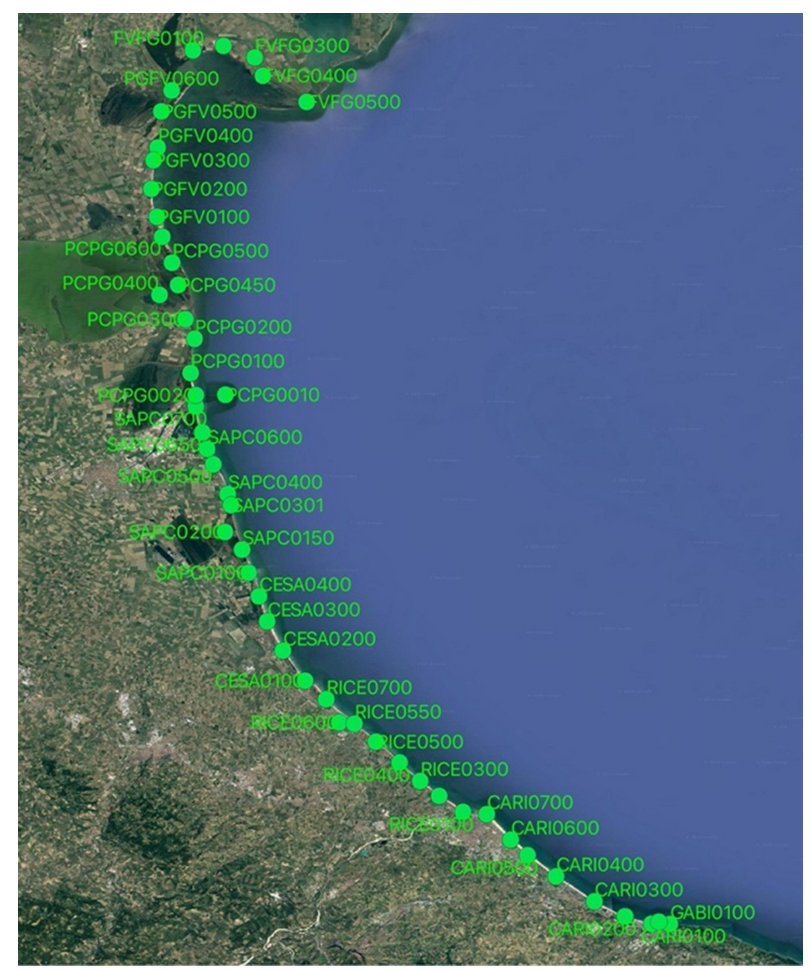

Fig. 1. Location of the 51 RGC benchmarks along the Emilia-Romagna Adriatic coastline.

where $h_{t}$ is the ellipsoidal height at the measurements epoch, $\Delta t$ is the time span ranging from such epoch and 2018.0, and $\mathrm{v}_{\mathrm{s}}$ is the subsidence rate provided by the most recent model in the position of the considered point.

The orthometric heights were updated at 2018.0 by applying:

$$
\mathrm{H}_{2018.0}=\mathrm{H}_{\mathrm{t}}+\Delta t_{1} * \mathrm{v}_{\mathrm{s} 1}+\Delta t_{2} * \mathrm{v}_{\mathrm{s} 2}
$$

where $\mathrm{H}_{\mathrm{t}}$ is the orthometric height at the measurement epoch (mostly 2005, while 1999 in a couple of cases). $\Delta t_{1}$ and $v_{\mathrm{s} 1}$ are the time span and related subsidence velocities before 2012, whereas $\Delta t_{1}$ and $\mathrm{v}_{\mathrm{s} 1}$ are related to the period 2012-2018.0.

Starting from both the height values at 2018.0, the experimental undulation for each point has been calculated through the simple equation:

$$
\mathrm{N}=\mathrm{h}-\mathrm{H}
$$

Table 1 reports the values involved in Eq. 3 for each point of the RGC network considered in this work.

With the aim to estimate the a-priori accuracy of the experimental values for the geoid height, we combined the uncertainties of all the involved measures by applying the covariance propagation law. Because of the poor knowledge about the uncertainties to be considered, we focused on defining a single value for all the network instead 
Table 1. Ellipsoidal heights (Columns 2,6) and orthometric heights (Columns 3, 7) at the 2018.0 epoch. Columns 4 and 8 report the experimental undulations in the chosen benchmarks.

\begin{tabular}{l|l|l|l|l|l|l|l}
\hline RGC id & $\mathrm{h}(\mathrm{m})$ & $\mathrm{H}(\mathrm{m})$ & $\mathrm{N}(\mathrm{m})$ & RGC id & $\mathrm{h}(\mathrm{m})$ & $\mathrm{H}(\mathrm{m})$ & $\mathrm{N}(\mathrm{m})$ \\
\hline GABI0100 & 45.33 & 4.88 & 40.45 & SAPC0400 & 40.35 & 1.17 & 39.18 \\
\hline CARI0100 & 42.84 & 2.40 & 40.44 & SAPC0500 & 40.56 & 1.38 & 39.19 \\
\hline CARI0010 & 42.81 & 2.38 & 40.43 & SAPC0600 & 43.34 & 4.17 & 39.17 \\
\hline CARI0200 & 42.32 & 1.91 & 40.41 & SAPC0650 & 39.97 & 0.71 & 39.25 \\
\hline CARI0210 & 42.27 & 1.88 & 40.38 & SAPC0700 & 41.33 & 2.05 & 39.28 \\
\hline CARI0300 & 43.46 & 3.15 & 40.30 & PCPG0020 & 41.96 & 2.58 & 39.39 \\
\hline CARI0400 & 43.69 & 3.49 & 40.20 & PCPG0010 & 40.93 & 1.49 & 39.44 \\
\hline CARI0500 & 43.10 & 3.01 & 40.08 & PCPG0100 & 41.08 & 1.64 & 39.44 \\
\hline CARI0600 & 42.94 & 2.96 & 39.98 & PCPG0200 & 41.68 & 2.11 & 39.57 \\
\hline CARI0700 & 41.72 & 1.83 & 39.89 & PCPG0300 & 40.36 & 0.68 & 39.68 \\
\hline RICE0100 & 42.68 & 2.81 & 39.87 & PCPG0400 & 41.51 & 1.68 & 39.82 \\
\hline RICE0200 & 42.57 & 2.77 & 39.80 & PCPG0450 & 41.57 & 1.69 & 39.88 \\
\hline RICE0300 & 42.33 & 2.57 & 39.76 & PCPG0500 & 41.56 & 1.58 & 39.98 \\
\hline RICE0400 & 42.85 & 3.29 & 39.56 & PCPG0600 & 41.93 & 1.78 & 40.14 \\
\hline RICE0500 & 41.55 & 1.97 & 39.58 & PGFV0100 & 42.08 & 1.82 & 40.26 \\
\hline RICE0550 & 41.01 & 1.49 & 39.51 & PGFV0200 & 44.11 & 3.74 & 40.37 \\
\hline RICE0600 & 41.83 & 2.36 & 39.47 & PGFV0300 & 43.14 & 2.53 & 40.61 \\
\hline RICE0700 & 42.01 & 2.54 & 39.47 & PGFV0400 & 42.73 & 2.08 & 40.65 \\
\hline CESA0100 & 40.99 & 1.60 & 39.39 & PGFV0500 & 41.06 & 0.20 & 40.86 \\
\hline CESA0200 & 41.40 & 2.10 & 39.30 & FVFG0500 & 42.20 & 1.43 & 40.77 \\
\hline CESA0300 & 41.17 & 1.96 & 39.21 & PGFV0600 & 43.58 & 2.61 & 40.97 \\
\hline CESA0400 & 40.74 & 1.63 & 39.11 & FVFG0400 & 43.07 & 2.00 & 41.07 \\
\hline SAPC0100 & 43.01 & 3.90 & 39.10 & FVFG0300 & 42.44 & 1.30 & 41.14 \\
\hline SAPC0150 & 40.58 & 1.50 & 39.08 & FVFG0100 & 41.77 & 0.55 & 41.22 \\
\hline SAPC0200 & 40.49 & 1.39 & 39.10 & FVFG0200 & 39.35 & -1.92 & 41.27 \\
\hline SAPC0300 & 41.41 & 2.24 & 39.17 & & & & \\
\hline
\end{tabular}

of a specific one for each benchmark. The accuracy for the subsidence models $\left(\sigma_{\text {subs }}\right)$ can be considered about $2 \mathrm{~mm} /$ years for both the selected periods as stated in [13, 14]. The accuracy of the orthometric heights $\left(\sigma_{\mathrm{H}_{\mathrm{i}}}\right)$ provided by spirit levelling campaigns can be considered about $7 \mathrm{~mm}$, as declared by the involved authorities [15]. For what concerns the levelling measures carried out in 2019 for the newly installed RGC points, we considered an accuracy equal to $1 \mathrm{~mm}\left(\sigma_{\text {lev }}\right)$ being the involved distances few hundred meters. The last uncertainty to be considered is that of the ellipsoidal height $\left(\sigma_{h}\right)$ obtained from the GNSS measures. For this evaluation, we considered the a-posteriori 
standard deviation obtained in the network adjustment, which average value over the 51 benchmarks is about $32 \mathrm{~mm}$.

Due to the error propagation, combining Eqs. 1-2 and 3, we obtained the accuracy associated to our experimental undulation values:

$$
\sigma_{\mathrm{N}}=\sqrt{\left(\sigma_{\mathrm{h}}\right)^{2}+\left(\sigma_{\mathrm{H}_{\mathrm{i}}}\right)^{2}+\left(\sigma_{\mathrm{lev}}\right)^{2}+\left(\Delta \mathrm{t}_{\mathrm{H}}+\Delta \mathrm{t}_{\mathrm{h}}\right)^{2} *\left(\sigma_{\text {subs }}\right)^{2}}
$$

where $\Delta t_{H}$ is the time span between the measuring epoch (assumed to be 2005) of the original orthometric heights and the final epoch 2018.0, and $\Delta \mathrm{t}_{\mathrm{h}}$ is the period between the average measuring epoch for the GNSS measures (2017.08) and 2018.0, both expressed in years. It is important to underline that for sake of simplicity the levelling measures have been considered for all the benchmarks, while actually, they involved only 11 points, thus obtaining a slightly overrated final value. Using the mentioned values, the a-priori undulation accuracy is about $4.3 \mathrm{~cm}$.

It was then possible to evaluate the differences between the experimental undulation values and the point-wise ones extracted from different existent geoid models.

The first comparison has been carried out by considering the official national geoid model of Italy, ITALGEO05. This is a gravimetric geoid, integrated with GPS/levelling data, developed by the Politecnico di Milano and adopted by IGM (Istituto Geografico Militare) [9, 16]. This model is delivered to users through gk2 format grids [17] which needed to be converted to allow easier use for our analysis. The gk2 grids have been formatted and densified through a TIN (Triangular Irregular Network) interpolation model with a $100 \mathrm{~m}$ spacing (about $0.001^{\circ}$ in latitude and longitude). Once obtained the final grid aligned to the ETRS89-ETRF2000 reference system, the geoid undulations over the chosen benchmarks have been extracted using Surfer software (https://www. goldensoftware.com/products/surfer).

The EGM2008 model was also considered, which is a global geopotential geoid released by the U.S. National Geospatial-Intelligence Agency (NGA) EGM Development Team [11]. The global model EGM2008 has proved to give comparable results with those of the ITALGEO05 and to be very effective in fitting data in the Central Mediterranean area [18], therefore we decided to test it. The EGM2008 point-wise undulations have been obtained using the Matlab geoidheight function, starting from the benchmarks geographic coordinates.

Finally, the ITG2009, which is the latest geoid model of Italy, has been considered. This regional model is based on the EGM2008, improving its precision and reliability [10] over the Italian area. The computing of the ITG2009 undulations has been carried out using the ISG web service (https://www.isgeoid.polimi.it/Geoid/geoid_rep.html).

Different geoid models usually show biases between them due to the specific choice adopted in terms of datum reference for each one [19]. The comparison between geoid realizations is therefore performed by subtracting to each one a bias that can be modelled through an oriented plane $[2,10,18]$. Because of the particular geometry of the RGC network, which is mostly aligned along a straight direction, we have chosen to solve the biases between the four considered realizations of the geoid undulations using a linear regression.

Differences between the regression lines will provide the generic information about the difference that one would find by applying a model instead of another one to correct 
ellipsoidal heights measured along the coastline. Differently, the analysis concerning the accuracy of each model in describing the shape of the geoid along the considered area will be discussed by looking at the residual values with respect to the regression lines.

\section{Results}

First of all, the experimental values of geoid undulation have been superimposed to the ones calculated in the corresponding positions using the three geoid models, as shown in Fig. 2. An overall agreement between the estimations can be noticed, with a better alignment between ITALGEO05 and the experimental values, whereas EGM2008 and ITG2009 are higher and close to each other. This result is not surprising since ITG2009 and EGM2008 are both based on the same computation with a difference in the fitting area [10] and the ITALGEO05 is the official reference for Italy, therefore the one also used to define the orthometric heights considered in the computation of the experimental $\mathrm{N}$.

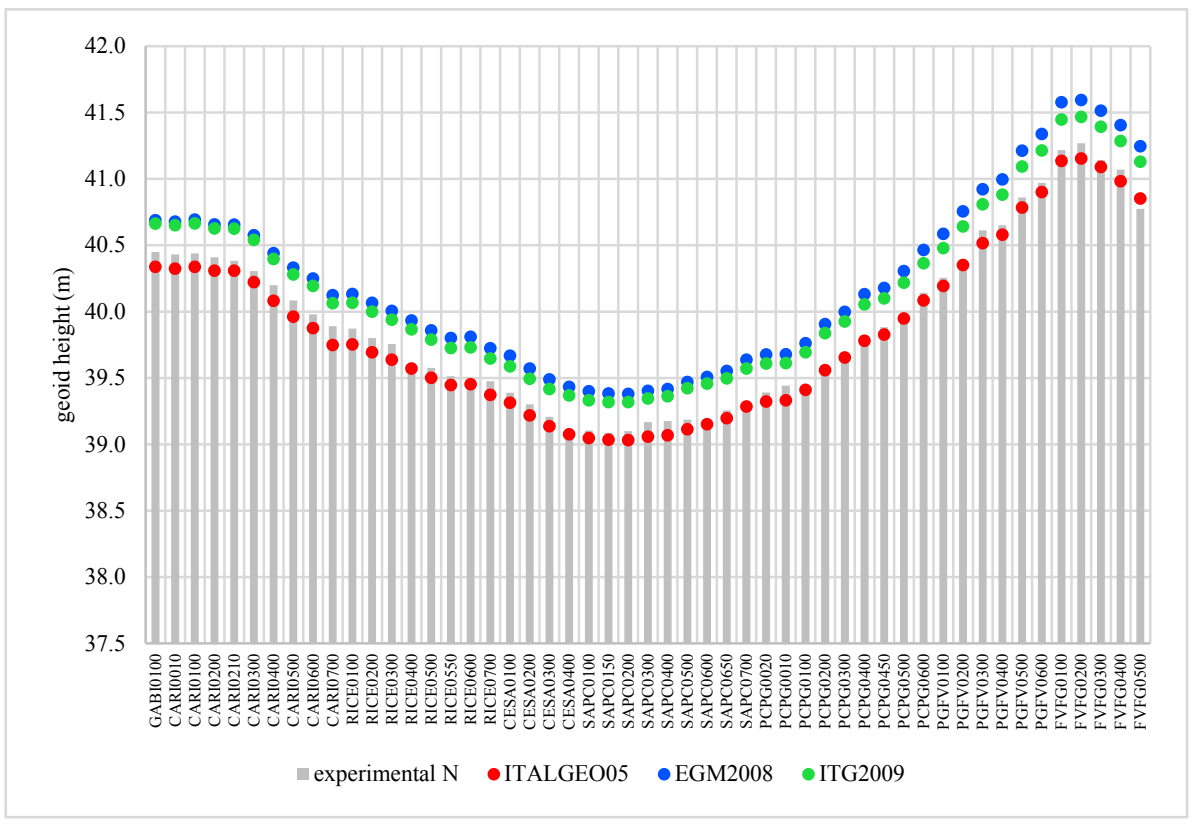

Fig. 2. The chart reports different definitions for the geoid heights over the chosen benchmarks: experimental GNSS-levelling values (grey bars), ITALGEO05 (red dots), EGM2008 (blue dots) and ITG2009 (green dots). (Color figure online)

The regression straight lines for each set of geoid heights were computed and are reported in Fig. 3. A general tilt can be seen moving along the coastline from south to north. The geoid height differences from south to north are $70 \mathrm{~cm}$ for the experimental 
data and $76.5 \mathrm{~cm}, 74 \mathrm{~cm}, 82 \mathrm{~cm}$ for the ITALGEO05, ITG2009 and EGM2008 respectively. The ITG2009 geoid model, which is the most recent and refined Italian model, shows the tilt closer to the experimental data.

The mean biases between the experimental data and the geoid models are $-7 \mathrm{~cm}$, $23 \mathrm{~cm}$ and $30 \mathrm{~cm}$ for the ITALGEO05, ITG2009 and EGM2008 respectively. All these values can be considered significant with respect to both the GNSS and spirit levelling precisions in the measurement of the height, therefore such biases have to be taken into account.

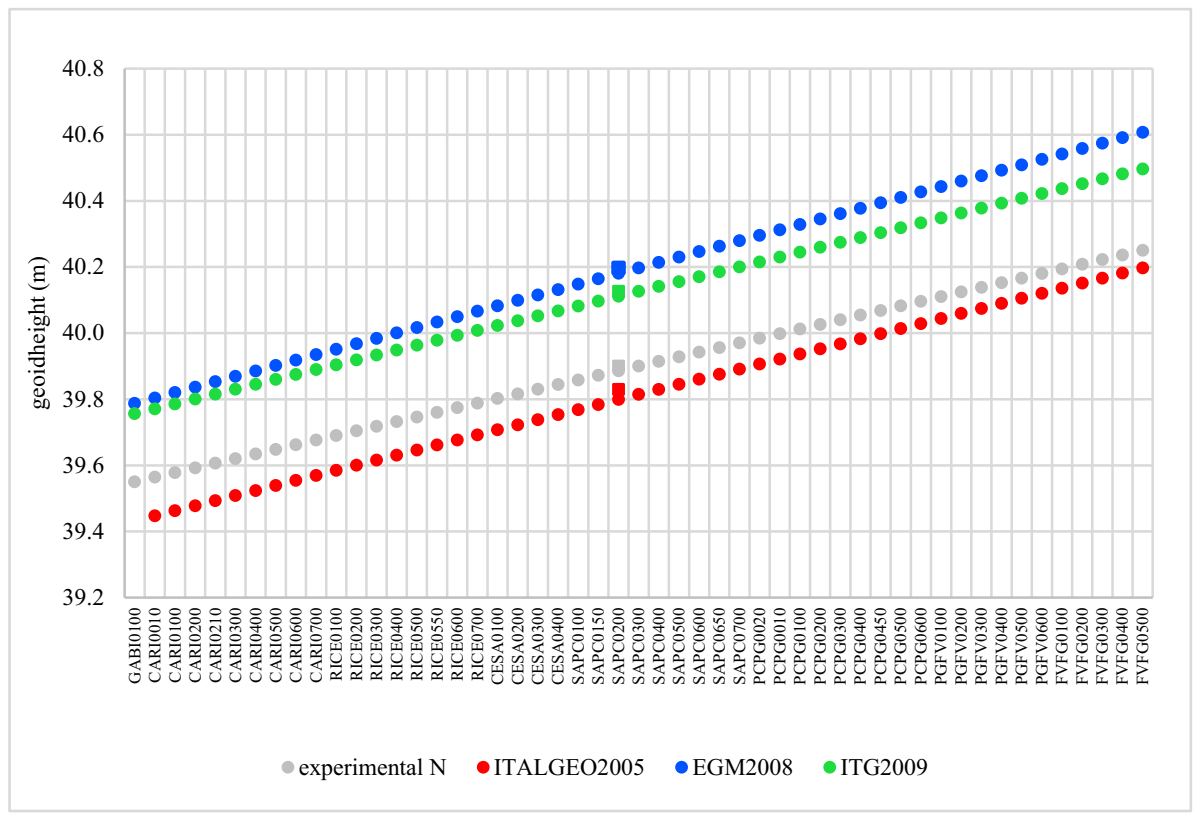

Fig. 3. Regression lines used to define and remove biases between geoid heights: experimental GNSS-levelling values (grey dots), ITALGEO05 (red dots), EGM2008 (blue dots) and ITG2009 (green dots). (Color figure online)

Residual values between each geoid undulation dataset and its regression line were computed to eliminate biases and trends. Then, the averaged value of these residuals relating to the three geoid models has been assumed as reference. Finally, the differences between each set of residuals and this reference were calculated and are reported in Fig. 4. The geoid models show to be scattered around their mean value with an RMS at the $1 \mathrm{~cm}$ level, which is within the accuracies declared for their determination [17, 18]. Nevertheless, local differences higher than $4 \mathrm{~cm}$ can be found over certain points, in particular between the ITALGEO05 and the EGM2008.

GNSS-levelling geoid heights are more scattered with respect to the reference, meaning $3.4 \mathrm{~cm}$ in terms of RMS with a couple of data up to $11 \mathrm{~cm}$ far. By considering a normal distribution of the measuring errors and a 3 sigma confidence interval, all these data are compatible with the a-priori uncertainty of $4.3 \mathrm{~cm}$. Differently, taking into account the 


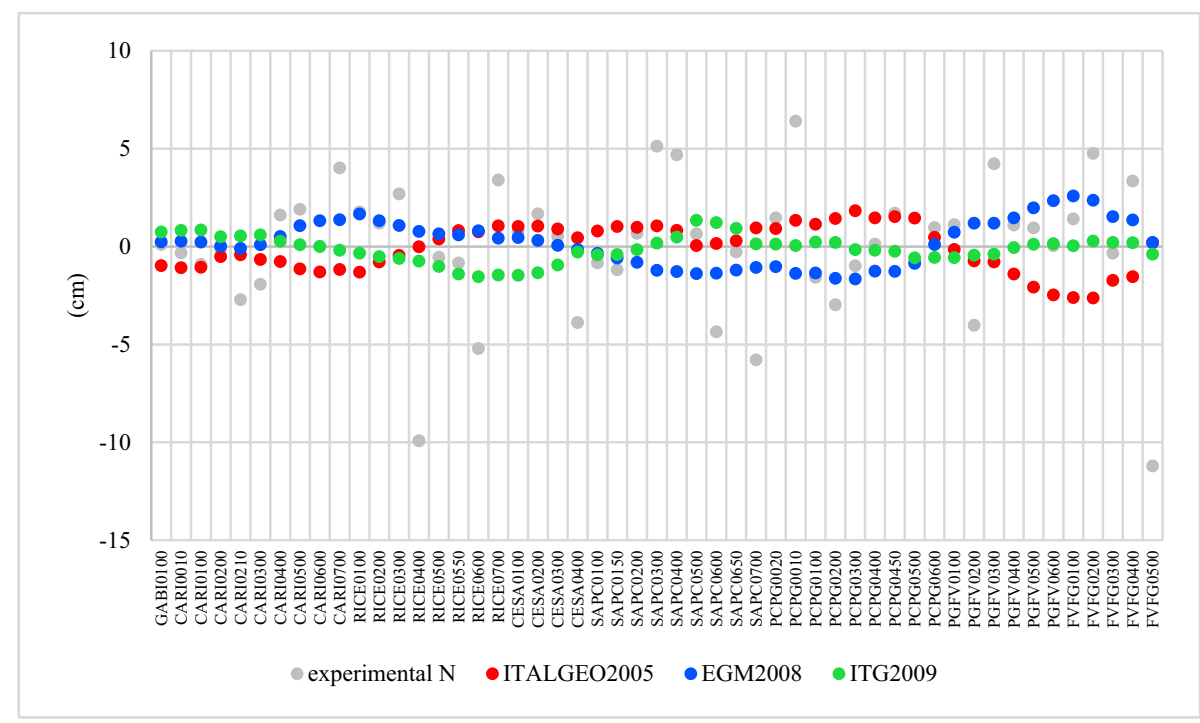

Fig. 4. Local differences between each geoid height determination and the reference defined as the mean value of the three considered gravitational models: experimental GNSS-levelling values (grey dots), ITALGEO05 (red dots), EGM2008 (blue dots) and ITG2009 (green dots). (Color figure online)

a-posteriori dispersion of the measures, the two points FVFG0500 $(-11.2 \mathrm{~cm})$ and RICE0400 $(-9.9 \mathrm{~cm})$ are not compliant with the measuring errors, which lead to different possible interpretations. On the one hand, these differences between experimental data can be due to gross errors in the measures, but on the other hand, these can be local deviations of the geoid due to particular conditions that cannot be modelled by gravimetric data used to define geoid models at the national/global scale. The latter hypothesis seems not to apply to the RICE0400 point since the area surrounding it is similar at all to the neighbouring coastline. Differently, the FVFG0500 point is located in a very particular area in the North of the regional coast, the Sacca di Goro lagoon, close to the lighthouse at the extremity of a small peninsula. This might induce a gradient in the gravity field close to the area unrecognized by large scale data.

\section{Discussion and Conclusion}

A definition of the geoid height alternative to the ones provided by three already available geoid models has been calculated over 51 points belonging to the RGC network along the Emilia-Romagna coastline. It was done by combining spirit levelling measures mainly performed in 2005 and GNSS coordinates estimated through static baselines between the years 2016 and 2019. The coherence of the experimental geoid heights has proven to be in line with the expected accuracy of the available data. Widespread biases of several centimetres between the experimental data and the models have been found, because of different references used to identify the geoid. The ITALGEO05 model is the closest to 
the experimental data, which was expected since it is the official Italian geoid model and the orthometric heights used in our computation are also referred to the national height datum. We eliminated these biases by subtracting regression straight lines to each geoid model for further analysis.

In terms of the shape of the geoid, it isn't possible to trust the experimental data to apply local corrections to the other models, since both the a-priori uncertainty and the a-posteriori scattering of the measures are too large. In order to use GNSS-levelling measurements to define local correction to the geoid height much more accurate measurements should be used. Let's now analyse this aspect in deeper detail. Looking at the uncertainties listed in Sect. 3 it is clear that errors due to spirit levelling are not impacting significantly on the final result given by Eq. 4. Bearing in mind that GNSS and spirit levelling data were not gathered at the same epoch and the whole area is undergoing subsidence phenomena, we can examine how the a-priori accuracy of the experimental geoid undulation would have improved with contemporary measuring campaigns. In such a case, the uncertainty changes from 4.3 to $3.2 \mathrm{~cm}$. Obviously, the same result can be found by considering subsidence models not affected by any uncertainty. The most impacting source of error seems to be the ellipsoidal height given by GNSS but note that reducing its uncertainty from 3.2 to $1 \mathrm{~cm}$ leads to a final uncertainty of the model of $3 \mathrm{~cm}$, which is an improvement very similar to what obtainable using simultaneous measurements. Finally, the combined use of contemporary acquired data and ellipsoidal height defined with $1 \mathrm{~cm}$ uncertainty lets Eq. 4 give an estimation of the final accuracy of the geoid height about $1.2 \mathrm{~cm}$, which is significantly better than what we dealt with. Such a case would only be possible by performing GNSS observing sessions much longer than $1-2 \mathrm{~h}$ in order to significantly improve the accuracy in the height definition.

Nevertheless, we want to highlight that the computed experimental geoid undulation can be used to transform ellipsoidal heights measured using satellite systems into orthometric heights in a way more coherent with the reference already defined in the considered area. Finally, it was fundamental to take into account the subsidence phenomena. In facts, if we estimate the local geoid heights without applying the corrections given by the subsidence models, an overall bias of about $2 \mathrm{~cm}$ is introduced, with differences up to $12 \mathrm{~cm}$ over the points affected by the higher subsidence ratio. This aspect is fundamental to be considered whenever dealing with surveys performed in different years.

\section{References}

1. Rapp, R.H., Wang, Y.M.: Geoid undulation differences between geopotential models. Surv. Geophys. 14, 373-380 (1993). https://doi.org/10.1007/BF00690565

2. Soycan, M., Soycan, A.: Comparison of several techniques for fitting of the EGM08 to GPS/leveling datum. Arab. J. Sci. Eng. 39(7), 5637-5651 (2014). https://doi.org/10.1007/ s13369-014-1136-1

3. Bjelotomić Oršulić, O., Markovinović, D., Varga, M., Bašić, T.: The impact of terrestrial gravity data density on geoid accuracy: case study Bilogora in Croatia. Surv. Rev. 52(373), 299-308 (2020)

4. Oluyori, P.D., Ono, M.N., Eteje, S.O.: Computations of Geoid undulation from comparison of GNSS/levelling with EGM 2008 for Geodetic applications. Int. J. Sci. Res. Publ. 8(10), 235-241 (2018). https://doi.org/10.29322/IJSRP.8.10.2018.p8230 
5. Vecchi, E., et al.: Third beach nourishment project with submarine sands along EmiliaRomagna coast: geomatic methods and first monitoring results. Rend. Fis. Acc. Lincei, 31, 79-88 (2020) https://doi.org/10.1007/s12210-020-00879-w

6. Aguzzi, M., et al.: Stato del litorale emiliano-romagnolo al 2018. Erosione e interventi di difesa, Bologna, Arpae Emilia Romagna, I quaderni di Arpae (2020)

7. Mancini, F., Grassi, F., Cenni, N.: A workflow based on SNAP-StaMPS open-source tools and GNSS data for PSI-based ground deformation using dual-orbit sentinel-1 data: accuracy assessment with error propagation analysis. Remote Sens. 13, 753 (2021). https://doi.org/10. 3390/rs13040753

8. Teatini, P., Ferronato, M., Gambolati, G., Bertoni, W., Gonella, M.: A century of land subsidence in Ravenna. Italy. In: Environ. Geol. 47, 831-846 (2005). https://doi.org/10.1007/s00 254-004-1215-9

9. Barzaghi, R., Borghi, A., Carrion, D., Sona, G.: Refining the estimate of the Italian quasigeoid. In: Bollettino di Geodesia e Scienze affini, vol. 3, pp. 146-157 (2007)

10. Corchete, V.: The high-resolution gravimetric geoid of Italy: ITG2009. J. Afr. Earth Sci. 58, 580-584 (2010)

11. Pavlis, N.K., Holmes, S.A., Kenyon, S.C., Factor, J.K.: The development and evaluation of the Earth Gravitational Model 2008 (EGM2008). J. Geophys. Res. Solid Earth 117, B04406 (2012). https://doi.org/10.1029/2011JB008916

12. Bitelli, G., et al.: Updating the subsidence map of Emilia-Romagna region (Italy) by integration of SAR interferometry and GNSS time series: the 2011-2016 period. Proc. IAHS 382, 39-44 (2020)

13. Emilia-Romagna, A.R.: Rilievo della Subsidenza nella pianura Emiliano-Romagnola. Relazione finale (2012)

14. Emilia-Romagna, A.R.: Rilievo della Subsidenza nella pianura Emiliano-Romagnola. Relazione finale (2018)

15. Emilia-Romagna, A.R.: Misura della rete regionale di controllo della subsidenza, misura di linee della rete costiera non comprese nella rete regionale, rilievi batimetrici. Relazione Finale (2001)

16. International Service for the Geoid (ISG). https://www.isgeoid.polimi.it/Geoid/Europe/Italy/ italgeo05_g.html. Accessed 08 Jan 2021

17. Prezioso, G., Pepe, M., Santamaria, R.: Confronto, su territorio campano, tra modello geoidico EGM2008 e modello di ondulazione da grigliati (2012). https://doi.org/10.13140/RG.2.1. 4354.8003

18. Barzaghi, R., Carrion, D.: Testing EGM2008 in the central mediterranean area, external quality evaluation. Reports of EGM08. Newton's Bull 4, 133-143 (2009)

19. Barbarella, M., Barzaghi, R., Dominici, D., Fiani, M., Gandolfi, S., Sona, G.: A comparison between the Italgeo' 95 and GPS/Leveling data along the coast of Italy. J. Phys. Chem. Earth (ISSN: 1474-7065) 23(1), 81-86 (1998). [SCOPUS ref. 2-s2.0-0031870497] 
Open Access This chapter is licensed under the terms of the Creative Commons Attribution 4.0 International License (http://creativecommons.org/licenses/by/4.0/), which permits use, sharing, adaptation, distribution and reproduction in any medium or format, as long as you give appropriate credit to the original author(s) and the source, provide a link to the Creative Commons license and indicate if changes were made.

The images or other third party material in this chapter are included in the chapter's Creative Commons license, unless indicated otherwise in a credit line to the material. If material is not included in the chapter's Creative Commons license and your intended use is not permitted by statutory regulation or exceeds the permitted use, you will need to obtain permission directly from the copyright holder.

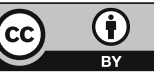

